\title{
Norwegian Open Fracture Management System: Outcomes After 10 Years Working in Low-Resource Settings in Cambodian Hospitals
}

\author{
Nenad B. Tajsic; ${ }^{1} \odot$ Sigrunn H. Sørbye; ${ }^{2}$ Sophy Nguon; ${ }^{3}$ Vannara Sokh; $;{ }^{3}$ Aymeric Lim ${ }^{4}$
}

1. Department of Orthopedic Trauma Surgery, University Hospital of North Norway, Tromsø, Norway

2. Department of Mathematics and Statistics, UiT - The Arctic University of Norway, Tromsø, Norway

3. Military Region 5 Hospital, Battambang, Cambodia

4. Department of Orthopedic Surgery, National University Hospital of Singapore, Singapore

Correspondence:

Nenad B. Tajsic, MD, PhD

Department of Orthopedic Trauma Surgery

University Hospital of North Norway

N-9038 Tromsø, Norway

E-mail address: nenad.tajsic@unn.no

Conflicts of interest/funding: There are no conflicts of interest, copyright constraints, or industry funding to report for any of the authors. The views expressed in this article are those of the authors and do not reflect the policy or position of any institution.

Keywords: classification system; global surgery; open fracture; rural settings; teaching

\section{Abbreviation:}

GHOIS: Ganga Hospital Open Injury Score

Received: May 13, 2021

Revised: September 11, 2021

Accepted: September 29, 2021

\section{doi:10.1017/S1049023X21001291}

(C) The Author(s), 2022. Published by Cambridge University Press on behalf of the World Association for Disaster and Emergency Medicine. This is an Open Access article, distributed under the terms of the Creative Commons Attribution licence (https:// creativecommons.org/licenses/by/4.0/), which permits unrestricted re-use, distribution, and reproduction in any medium, provided the original work is properly cited.

\begin{abstract}
Introduction: The treatment of open lower limb fractures represents a major challenge for any trauma surgeon, and this even more so in resource-limited areas. The aim of the study is to describe the intervention, report the treatment plan, and observe the effectiveness of the Norwegian Open Fracture Management System in saving lower limbs in rural settings.

Materials and Methods: A retrospective and prospective interventional study was carried out in the period 2011 through 2017 in six rural hospitals in Cambodia. The fractures were managed with locally produced external fixators and orthosis developed in 2007. Based on skills and living locations, two local surgeons and one paramedic without reconstructive surgery experience were selected to reach the top of the reconstructive ladder and perform limb salvage surgeries. This study evaluated 56 fractures using the Ganga Hospital Open Injury Score (GHOIS) for Gustilo-Anderson Type IIIA and Type IIIB open fracture classification groups.

Results: The primary success rate in open tibia fractures was 64.3\% (95\% CI, 50.3 - 76.3). The average treatment time to complete healing for all of the patients was 39.6 weeks $(95 \%$ CI, 34.8 - 44.4). A percentage of $23.2 \%$ ( $95 \%$ CI, 13.4 - 36.7) experienced a deep infection. Fifteen of the patients had to undergo soft tissue reconstruction and 22 flaps were performed. Due to non-union, a total of 15 bone grafts were performed. All of the 56 patients in the study gained limb salvage and went back to work.

Conclusion: The given fracture management program proves that low-resource countries are able to produce essential surgical tools at high quality and low price. Treatment with external fixation and functional bracing, combined with high-level training of local surgeons, demonstrates that a skilled surgical team can perform advanced limb salvage surgery in low-resource settings.
\end{abstract}

Tajsic NB, Sørbye SH, Nguon S, Sokh V, Lim A. Norwegian open fracture management system: outcomes after 10 years working in low-resource settings in Cambodian hospitals. Prehosp Disaster Med. 2022;37(1):90-100.

\section{Introduction}

Treatment of open injuries and severely mangled limbs represents a major challenge for any trauma surgeon around the world. The incidence of such injuries is unfortunately increasing, especially in developing countries. This is to a large extent due to a steep increase in road traffic accidents. In low-resource settings, limb salvage is particularly challenging as the direct and indirect costs of the primary and secondary treatment of these injuries are high. Without any governmental welfare or social support, these injuries represent a severe burden for patients, their families, and the society (Figure 1). ${ }^{1,2}$

Transfer of equipment from developed countries to low-resource countries as part of humanitarian aid can be beneficial. ${ }^{3}$ However, such aid only represents a temporary solution which does not give security to the recipients in the long run. The challenge is therefore to find methods for limb salvage surgery which are feasible in low-resource settings. ${ }^{4}$ In most developed countries, larger hospitals typically have multi-disciplinary teams for lower limb reconstruction, including orthopedic surgeons, plastic surgeons, and infectious disease specialists. Those special skills are not available in Cambodian hospitals for the time being.

The aim of this study was to demonstrate the first successful limb salvage program in a developing country. The program included locally produced medical tools, the use of a simple classification system on open fracture management, and supervision and temporary presence of surgical expertise from Norway. 


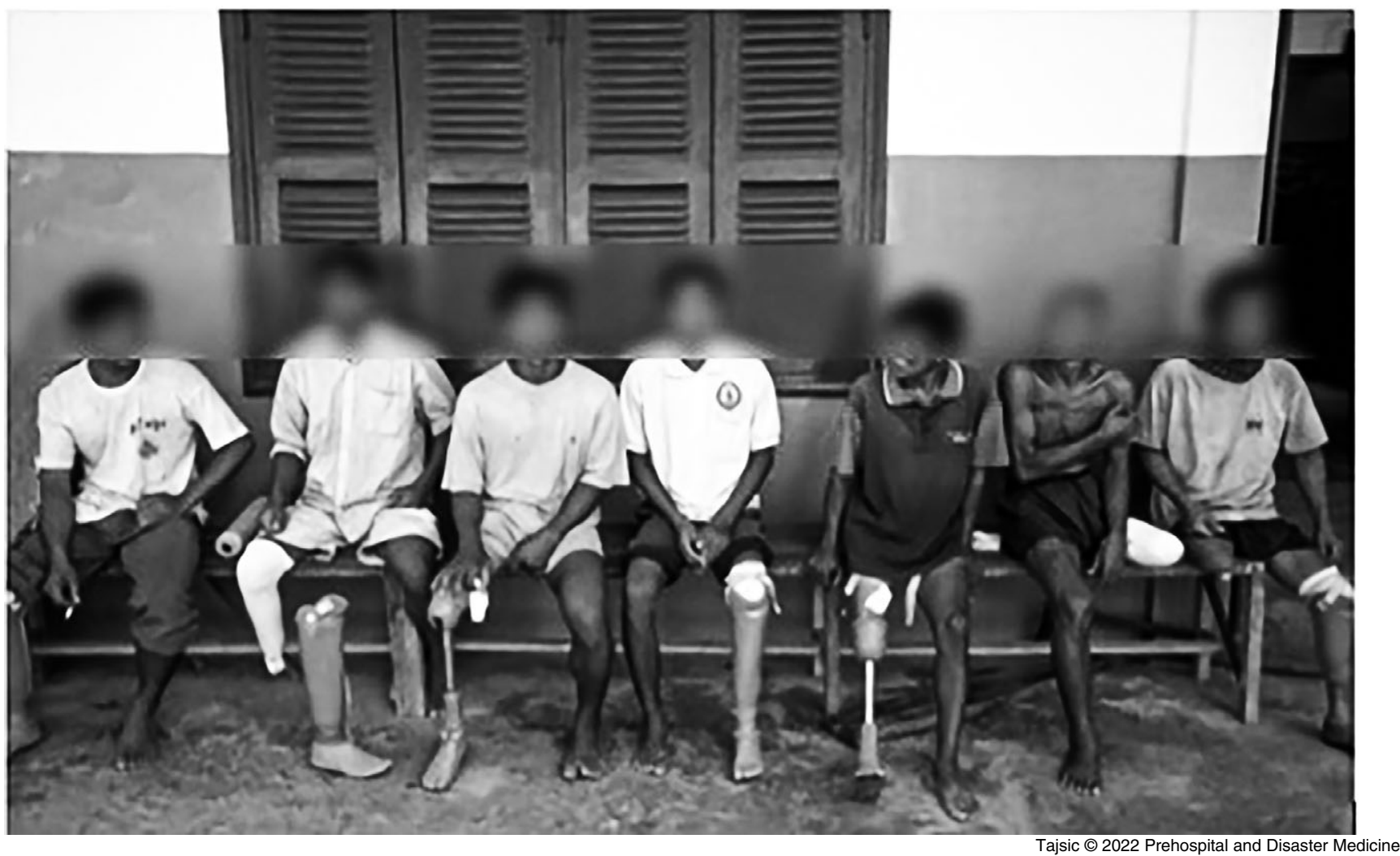

Figure 1. Disability and Poverty as a Global Challenge: Save Limbs, Save Lives.

\section{Material and Methods}

This was a clinical interventional study with retrospective and prospective data collection. The study population was patients with open tibia fractures managed with external fixation and secondary orthosis at low-resource hospitals in Cambodia. The reference population for the study was patients with isolated open fractures in the leg. From January 2011 through December 2017, a total of 56 patients with open tibia fractures managed at six hospitals in northern Cambodia were consecutively registered for the study.

\section{Intervention 1: Development and Production of External Fixator and Locally Made Orthosis}

During the period 2007 through 2010, employees at the Tromsø Mine Victim Resource Center in Norway and the Trauma Care Foundation in Cambodia developed a fixator and orthosis which could be produced in low-resource settings. The external fixator frame was made from type 316L stainless steel at a local 30-bed hospital workshop in the village Sompouv Luon in northern Cambodia. The biomechanical strength of the frame, including $6 \mathrm{~mm}$ self-drilled bone pins, clamps, and balancing bars, was tested and approved by the SINTEF Materials and Chemistry Testing Laboratory in Norway (SINTEF 2008-05-30, ref.no. 804023.17). ${ }^{4}$ Testing results showed that the chemical composition of the pins was similar to authentic stainless steel of type SS316/SS316L which is used for medical instruments and fixation screws. The new external fixator frame was accepted and approved by the Secretary of State for Health at the national workshop in Phnom Penh (Cambodia) on June 31, 2011.

The external fixation did not allow for full weight bearing. In order to impose some fracture load and stimulate bone formation, the external fixation was removed when bone callus started to form.
Further, a below-knee orthosis was applied which included a circular plastic brace that supported the fracture and allowed increased weight bearing. The product was made from local plastic PVC water pipes. These were shaped carefully to fit the injured limb. The orthosis was made in two pieces consisting of one front and one back panel. Small holes were drilled into the brace to allow ventilation. Patients were able to adjust the support by a Velcro strap. ${ }^{4}$

\section{Intervention 2: Clinical Training and Supervision}

Based on their skills and location of practice, three surgeons (two doctors and one paramedic) were selected to reach the top of the reconstructive ladder in open fracture management. ${ }^{5}$ None of the pre-selected surgeons and paramedic had been engaged in limb salvage surgery before. A pre-selected surgical team was chosen for internet collaboration including a team from Battambang, Cambodia (VS, SN) and one senior consultant from Norway (NT). In addition to providing continuous theoretical and practical supervision, the senior consultant from Norway was present at Battambang for five weeks per year from 2011 until 2017. A clinical study has been approved by National Ethics Committee for Health Research, Cambodia (ref. no.004NECHR).

All of the 56 patients with an open fracture of the leg were categorized according to the Gustilo-Anderson Type IIIA and Type IIIB classification groups. ${ }^{6}$ Further, the Ganga Hospital Open Injury Score (GHOIS) was used to allocate scores for injuries to skin and fascia over and around a fracture, to the bone fracture configuration and muscle-tendon unit injury, ${ }^{7,8}$ with added points for comorbidities. A cutaneous and bone score of three or greater was predictive of complex soft tissue and bone reconstruction and a score of 12 or greater was predictive of amputation. ${ }^{9}$ Pre- and post-operative drawings in an operation book and photo 


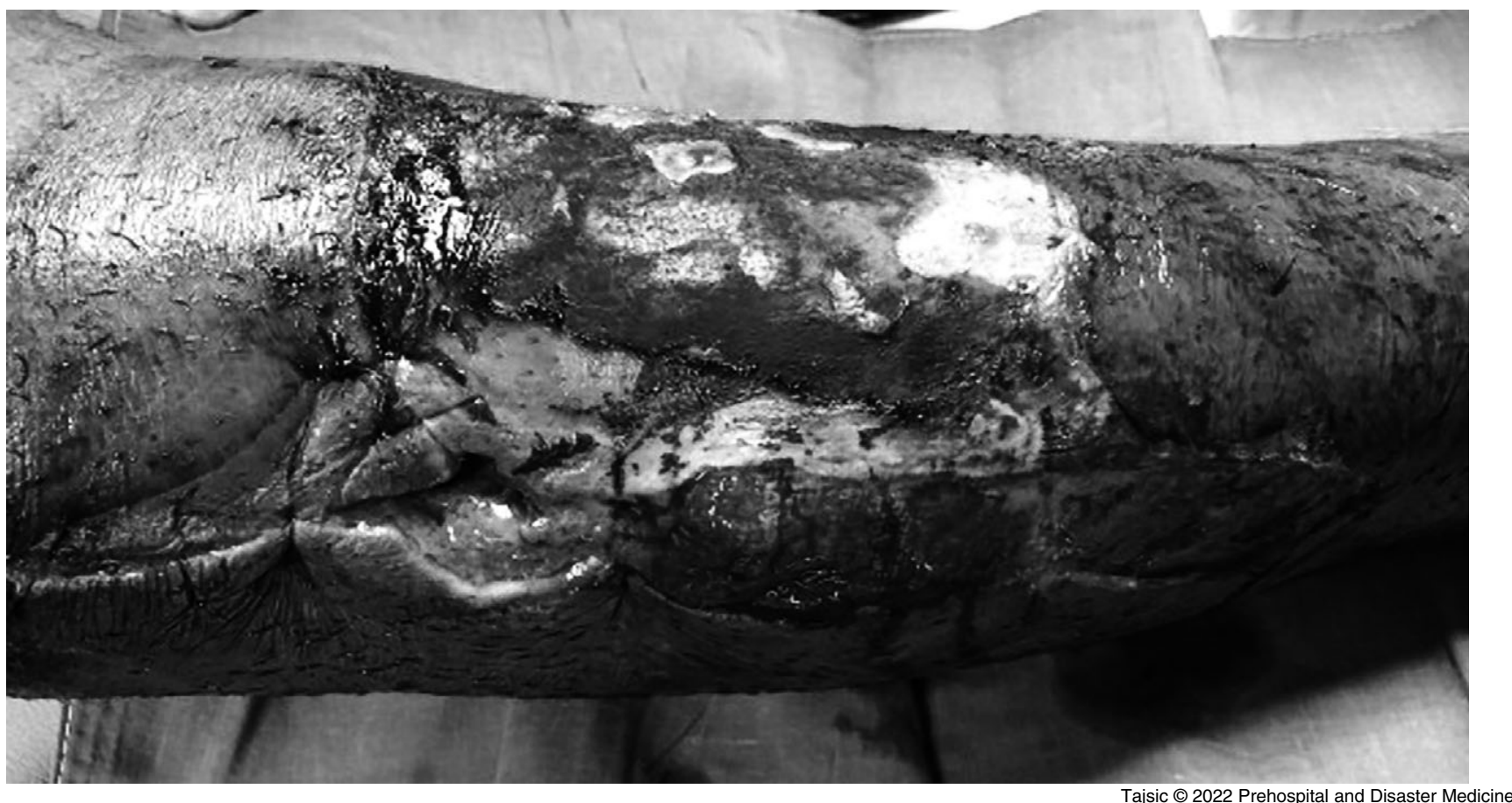

Figure 2a. 53-Year-Old Man with Severe Limb-Threating Injury after being Struck by Car.

documentation of soft tissue injuries were mandatory to understand the use of the open fracture classification systems (Figures $2 \mathrm{a}, 2 \mathrm{~b}$, $2 \mathrm{c}, 2 \mathrm{~d}, 2 \mathrm{e}$, and $2 \mathrm{f}$ ).

After debridement of soft tissue and bone, the bone pins were placed through healthy tissue proximal and distal to the fracture. Some, but not all, of the study patients received prophylactic antibiotic treatment at the time of primary surgery, if antibiotics were in fact available. The fracture was aligned under direct vision and the frame was fixed. There was no image intensifier in the operation theaters and the only imaging available was $\mathrm{x}$-rays taken before and after surgery. The patient was mobilized on crutches the first post-operative day with a maximum weight load of $5 \mathrm{~kg}$. If possible, an immediate primary skin closure technique was used to reduce the need for unnecessary soft tissue reconstructions. ${ }^{78}$ In cases where soft tissue cover was needed, hinged or perforator flap surgery techniques were developed. ${ }^{10-12}$ For treatment of post-traumatic bone defects, acute or in delayed unions, three techniques were used: autologous bone transplantation from the iliac crest, vascularized fibula graft, and "open sky" grafting as described by Papineau. ${ }^{13}$

During the first two months, the selected surgeon monitored the fracture position and adjusted the compression of the fracture. At weeks six through eight, $\mathrm{x}$-rays were taken for observation of callus formation. During this period, full weight bearing was allowed when an adequate bridging callus was visible. The union of the fracture was defined as the presence of a bridging callus in three cortices based on the radiograph. When callus was formed and the fracture was semi-stable by manual testing, the frames with bone pins were removed and a technician took a plaster mold to make the orthosis. From this point, the patient was encouraged to bear weight until just below the pain limit. The patient came for clinical and x-ray check-ups at weeks $12-14$ and weeks 20-22. The orthosis was removed when there was definitive bone healing without signs of infection. Cases of non-union and osteomyelitis were managed by secondary debridement of soft tissue and bone, fibula osteotomy, bone grafting, and soft tissue flap transposal. An external fixator and secondary orthosis were used also for the cases with primary failure.

\section{Variable and Data Collection}

The main outcome variables in the study were bone healing, scores of the injuries according to the Gustilo and GHOIS classification systems, and categorical variables to register complications (Figure 3). Bone healing was defined by two indicators: good callus on the fracture side, and capacity of full weight bearing without pain. The diagnosis of soft tissue infection was based on three clinical signs: local inflammation, pus from the wound, or gas production. At least one of these three indicators needed to be present to establish the diagnosis. Osteomyelitis was diagnosed as a deep infection based on $\mathrm{x}^{-}$ ray findings of sclerosing or sequester formation.

The data were collected by local medical doctors who were trained as research assistants in each of the study hospitals. The entire research team validated the $\mathrm{x}$-ray data. The collected information was coded and consecutively registered in a Microsoft Excel spread sheet (Microsoft Corp.; Redmond, Washington USA).

Network communication was established offering 24-hour surveillance. Primary correspondence was by email, which included $\mathrm{x}$-ray and photos of the soft tissues in open fractures of the leg and an "Open Fracture Case Record Form" used for analysis. Inclusion and exclusion criteria for the study are described in Table 1.

The statistical analysis was performed using the software $\mathrm{R}$ (version 4.0.3; R Foundation for Statistical Computing; Vienna, Austria). This includes the use of $t$-distributed statistics to perform inferences for means (age and total healing time; t.test). Differences in duration of treatment times were tested using one-sided nonparametric Wilcoxon rank sum tests with continuity correction (wilcox.test), as these data were not normally distributed. Equality of proportions was tested using a two-sample z-test with 

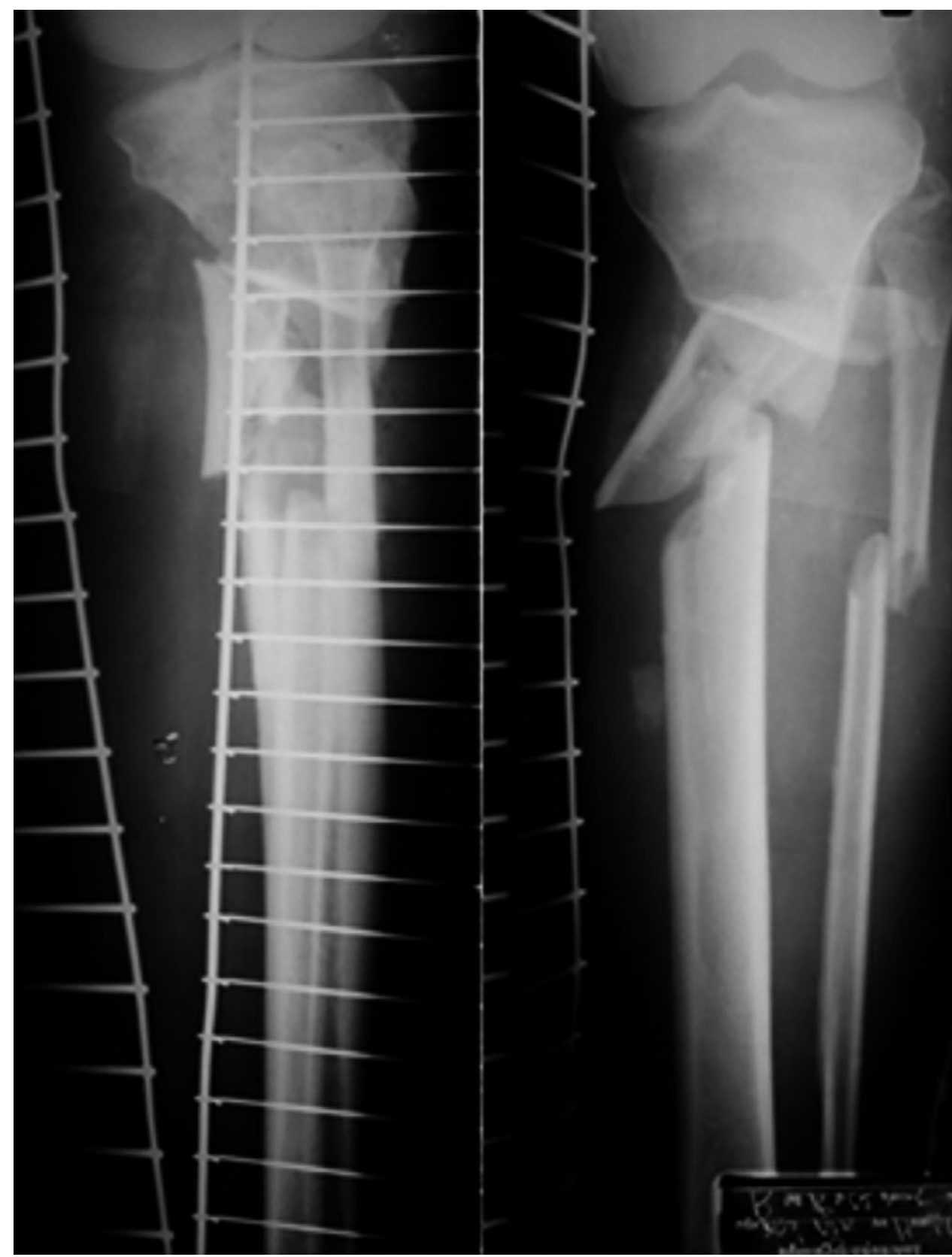

Figure 2b. Comminuted Open Fracture of the Tibia.

Tajsic @ 2022 Prehospital and Disaster Medicine

continuity correction, while the one-sample version was used to find confidence intervals for proportions. Confidence intervals for the median time to union for Type IIIA and Type IIIB fractures were found using nonparametric bootstrapping. The significance level of hypothesis tests was set equal to 0.05 .

\section{Results}

All of the study patients received primary treatment at one of the study hospitals. After meticulous debridement performed by the pre-selected reconstructive surgical team, a total of 56 patients with open leg fractures were categorized according to the GustiloAnderson and GHOIS classification system. Of the 56 fractures, 25 were of Type IIIA and 31 of Type IIIB.
Scores of the injuries were allocated according to the GHOIS sub-groups. Based on the individual scores for each sub-group, patients were classified as being in Group I (GHOIS $\leq 5)$ and Group II (GHOIS >5), the latter group consisting of approximately two-thirds (39/56) of the cases.

Table 2 displays the gender distribution, the mean age, and different treatment outcomes for the patients classified to Group I and Group II. In total, 89\% (50/56) of the patients were males. The mean age of patients was significantly higher in Group II than Group I $(\mathrm{P}=.013)$. As expected, the results reflected that duration of treatment increased significantly with the severity of the injury. The mean time using an external fixation increased from 12.9 weeks in Group I to 22.7 weeks in Group II $(\mathrm{P}=.003)$. The 


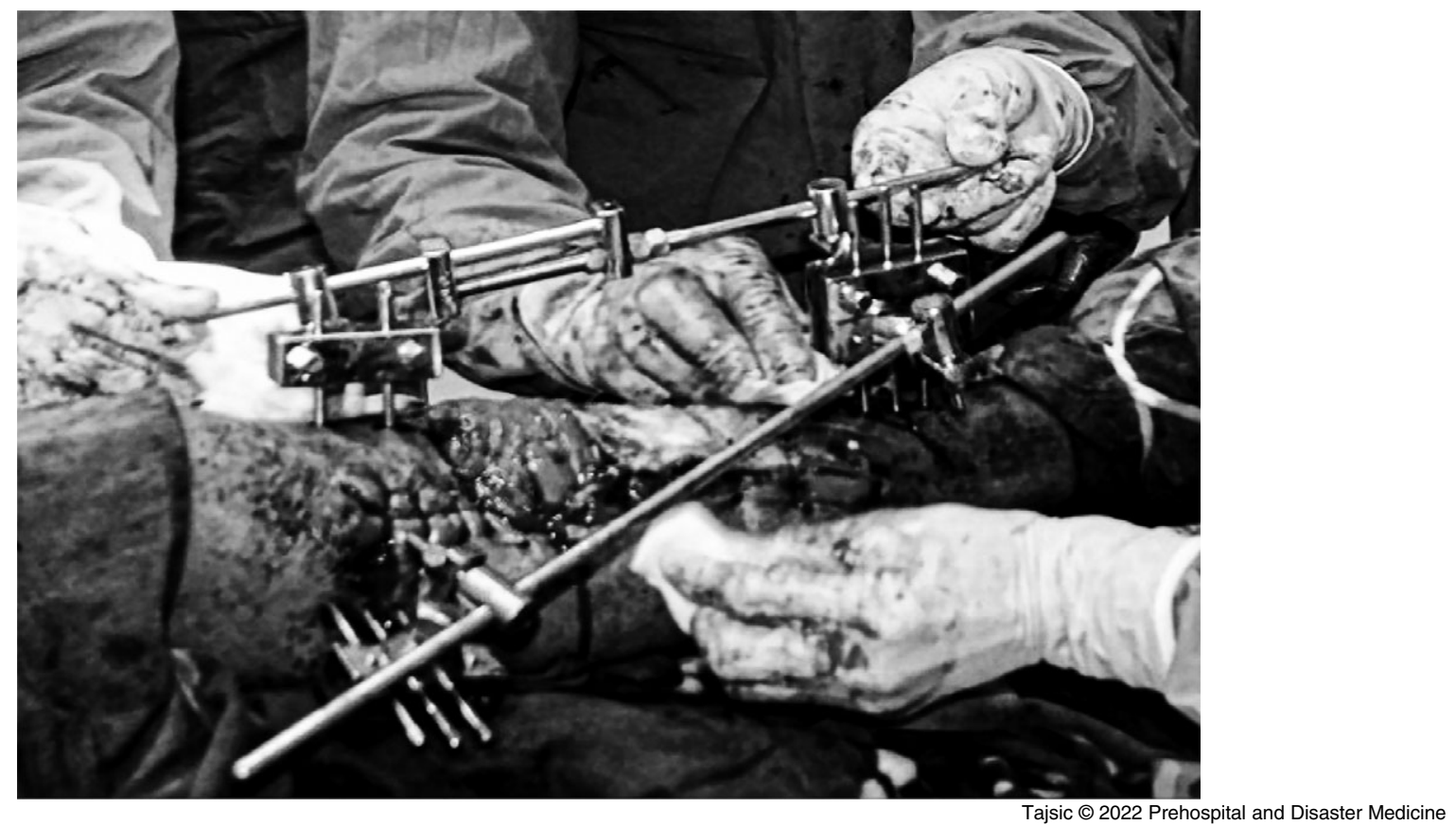

Figure 2c. Infected Plate has been Removed, Radical Debridement and Soft Tissue Coverage Done with Gastrocnemius Flap, Split-Thickness Skin Graft, and External Fixator Mounted.

corresponding mean times for using an orthosis increased by approximately four weeks from 16.6 weeks to 20.5 weeks ( $\mathrm{P}=$ $.017)$. The total mean time to union increased correspondingly from 29.5 to 44 weeks $(\mathrm{P}=.007)$. A total of 13 patients (23.2\%; 95\% CI, 13.4 - 36.7) experienced a deep infection. Fifteen of the patients had to undergo soft tissue reconstruction and 22 flaps were performed. All but one of the flaps and one vascularized fibula were done for patients in Group II. Due to nonunion, a total of 15 bone graftings were performed, all on patients in Group II.

The average treatment time to complete healing for all of the patients was 39.6 weeks (95\% CI, 34.8 - 44.4). In summary, the clinical outcome in fracture healing was good for 36 of the patients, implying a primary success rate in open tibia fractures of $64.3 \%$ (95\% CI, 50.3 - 76.3).

\section{Discussion}

To the authors' knowledge, this study on limb salvage surgery in low-resource settings in Cambodia is unique. The Norwegian Open Fracture Management program encompassed local production of medical equipment, the use of a simple classification system for the injuries, medical education to increase the capability of general surgeons and health workers, and on-going surgical support, either in person or remotely. The surgeons at the district hospitals found the external fixator easy to apply and the orthosis treatment was implemented effectively even at remote hospitals. External fixation in combination with orthosis treatment was used successfully in 15 cases with soft tissue reconstructions, non-union, and osteomyelitis. To increase interobserver agreement, ${ }^{7,14}$ the GHOIS classification system was used. The individual scores of GHOIS provided guidelines for treatment while the total score helped to decide on salvage and the prognostic outcome for a patient. All of the 56 patients in the study gained limb salvage and went back to work.

\section{Limitations}

However, there were several limitations of this study.

Firstly, the customized exclusion criteria induced a selection bias. Poor sterility conditions of the study hospitals left external fixation as the only method of choice for osteosynthesis of the injured limbs. The skill score for the participants was adopted to the rural settings as no microsurgery facilities were available (Figure 4). This means that all legs with open fractures with a GHOIS total score of 12 or greater were primary considered to need amputation.

Secondly, the study hospitals were spread across six provinces, some of them in remote areas. It was challenging for the researchers to monitor the study patients. However, the participating surgeons have known each other for many years and cooperated closely. Two of the surgeons (NT and SN) examined all study patients at least three times during the treatment period. Therefore, it is believed that all of the outcome variables were registered correctly.

Thirdly, missed diagnoses of asymptomatic infections and comorbidity should be considered. The type of bacteria, its virulence, and its susceptibility to antibiotics in the cases of post-traumatic osteomyelitis are other variables that are uncontrollable in this clinical model. As the observation period for successful primary treatment was relatively short (six to eight months), there might have been cases with low-grade occult osteomyelitis that did not become evident within this time period. However, because the study patients were granted treatment free of charge, it is believed that patients with late fistula formation and non-union would most likely have contacted their hospital. The authors therefore believe that few, if any, cases of treatment failure have been missed in this study.

Antibiotic prophylaxis is a poorly controlled variable in this study. There were no facilities such as a microbiology laboratory, and antibiotics were only utilized in $32 / 56$ patients. The deep infection rate for patients in Group II $(28.2 \%)$ is higher than a 


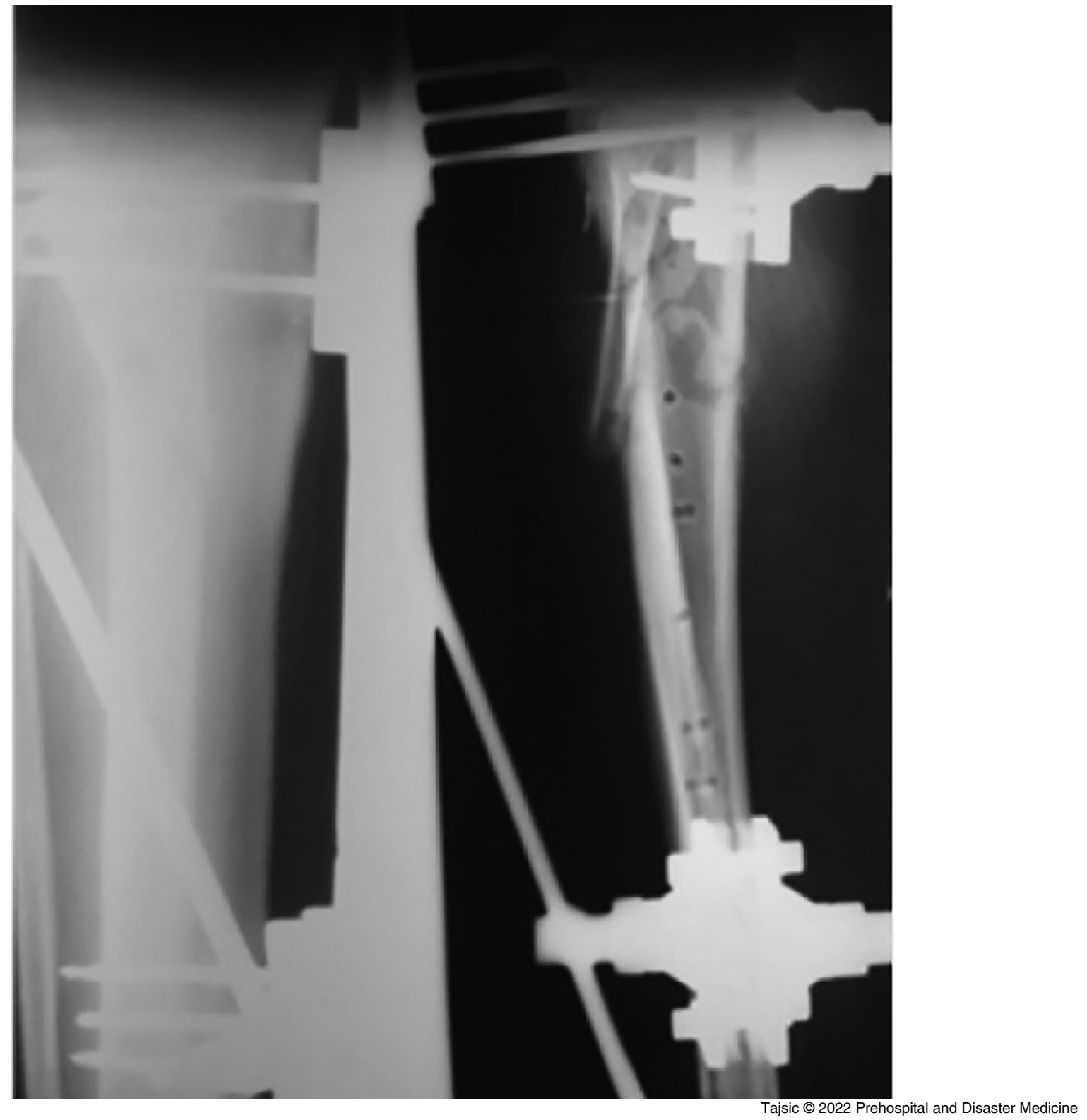

Figure 2d. Eight Weeks After Flap Surgery, X-Ray Shows New Bone Formation.

corresponding reported rate at Ganga hospital ${ }^{9}$ in which seven out of 51 patients (13.7\%) classified to Group II got a deep infection. However, this difference is not significant $(\mathrm{P}=.151)$. It is therefore believed that the lack of antibiotics had a minimal impact on the treatment outcomes in the study.

These results can be compared with outcomes reported in international trials of external fixators in tertiary hospitals with specialized teams for limb salvage surgery. A study from Thailand ${ }^{15}$ reported that the median union time in Type IIIA open fractures was 16 weeks (range 20 - 24) for 43/60 patients. For Type IIIB fractures (3/60 patients), the median union time was 20 weeks (range $20-21)$. As reported in the results, the corresponding median union times in this study were 29 weeks (95\% CI, 24 43) for Type IIIA fractures and 40 weeks (95\% CI, 30 - 54) for Type IIIB fractures. These results indicate that the fractures in this study showed longer healing time.
A study on 109 patients at the Ganga tertiary hospital showed that the mean time to union was 16 weeks (range $10-28$ ) for patients classified to Group I and 25 weeks (range 8 - 55) for patients classified to Group II. ${ }^{7}$ As reported in Table 2, the mean time to union was longer for both groups in this study. This can be due to the fact that in contrast to intramedullary nailing or plate fixation, a potential drawback of external fixation is that the frame cannot take weight loads.

Contrary to most trials of external fixation, this study shifted to functional bracing with orthosis at the time of the callus formation and weight bearing was encouraged. It is believed that the orthosis treatment was a key factor for the high success rate in this study. Based on this, the authors want to recommend a combined approach of external fixation with functional bracing, especially in low-resource areas where intramedullary nailing and plate osteosynthesis is untenable for reasons of hygiene and economics. 


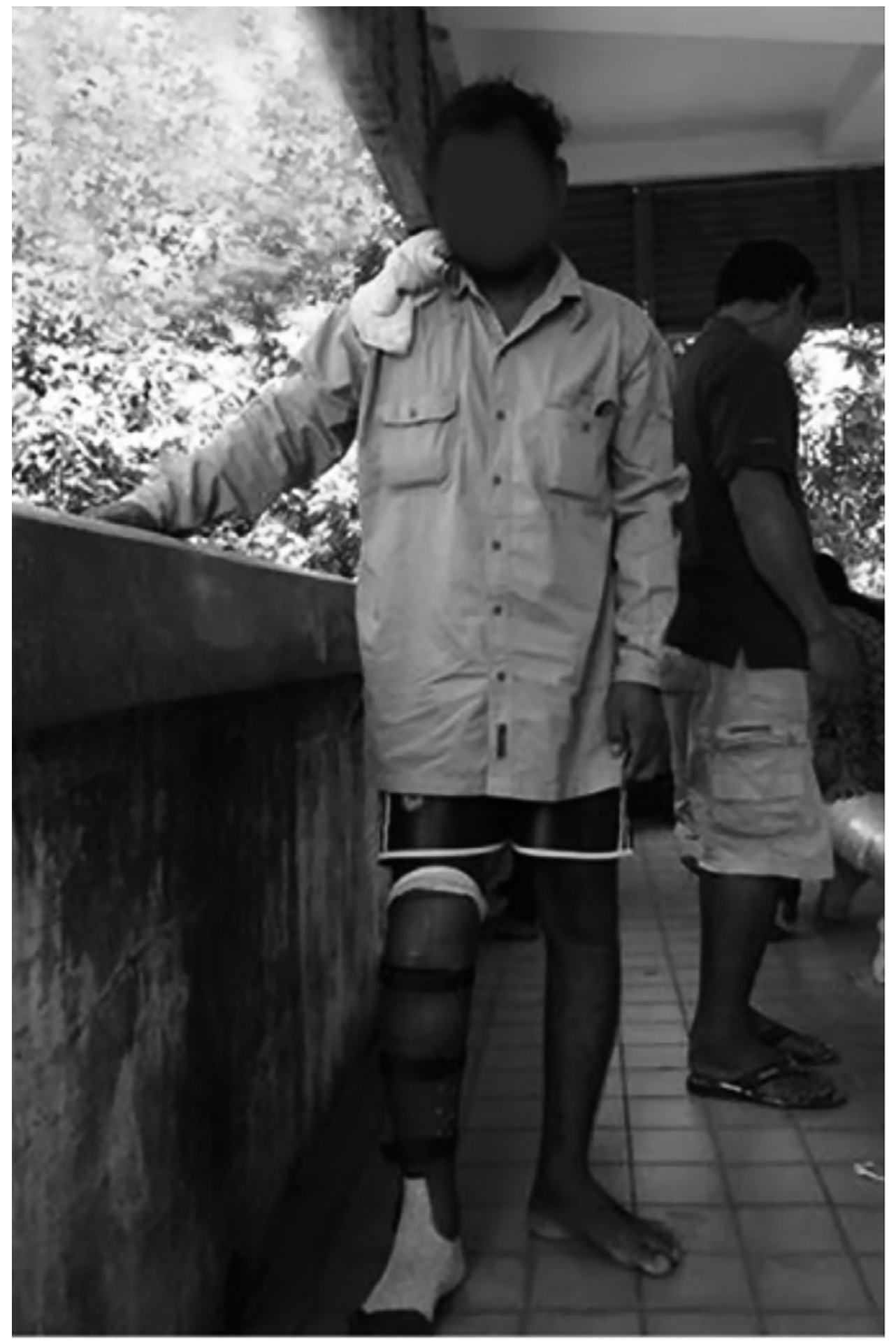

Tajsic (๑) 2022 Prehospital and Disaster Medicine

Figure 2e. External Fixator Removed and Patellar-Tendon-Bearing Orthosis has been made from PVC Water Pipes.

An important goal of the given clinical training program was to promote surgical expertise and independence of local health workers. After three years of practical education and hands-on surgery, the two surgeons and the one paramedic in this study were capable to perform mounting of the external fixator, soft tissue reconstruction, and bone transplantation on their own, achieving a skill score above three (Figure 4).
The authors believe that the described fracture management program has enhanced the standard of trauma treatment in Cambodian hospitals, implying a particular advantage for poor trauma victims. The market price of the Cambodian external fixation frame was US $\$ 50 /$ set. The cost of equivalent western brands is from US $\$ 6000$ to US\$10000, which is far beyond reach for lowincome countries. ${ }^{16}$ Wealthy families may send trauma victims for 


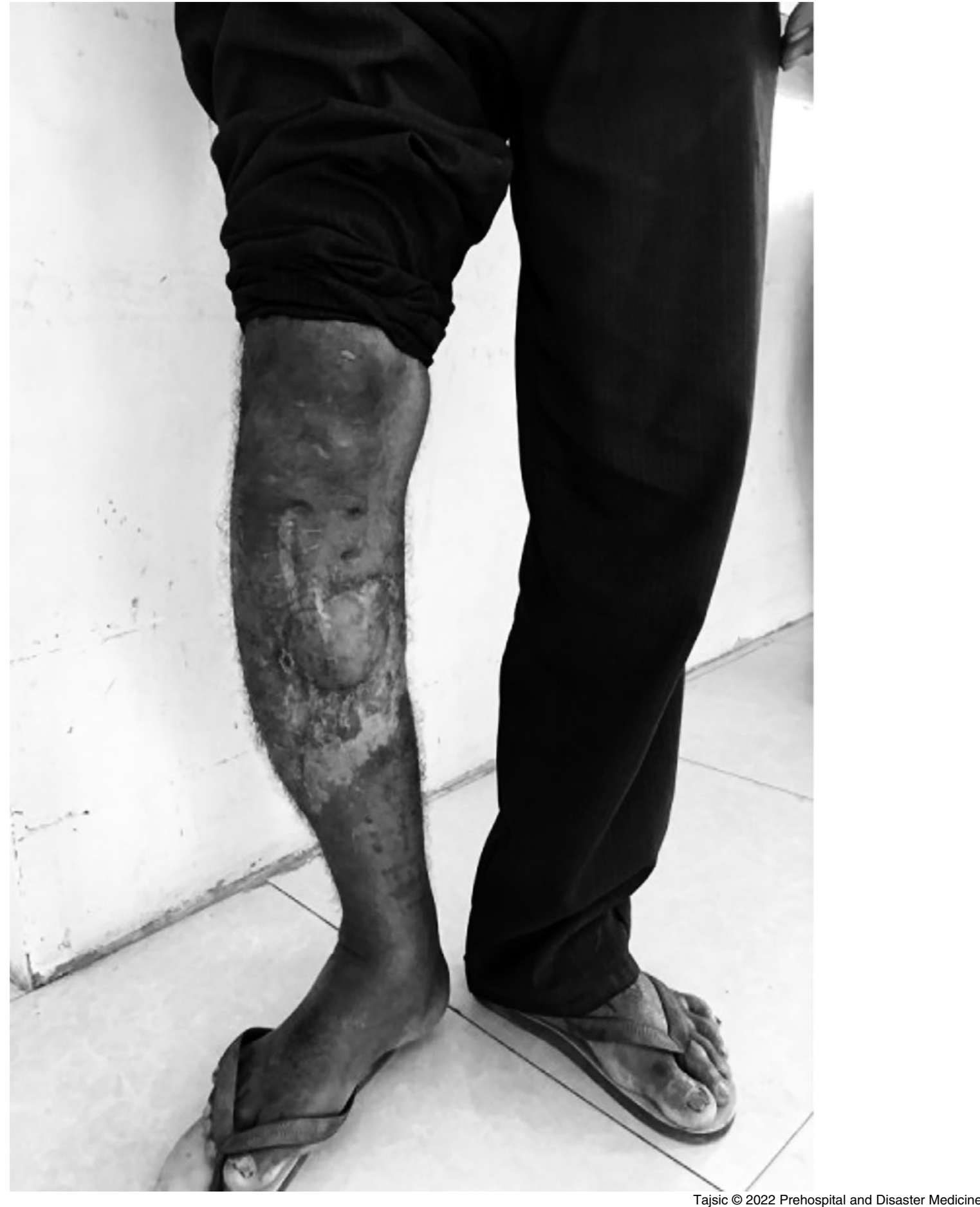

Figure 2f. Fracture Healed after 10 Months, Full Weight Bearing.

treatment at private clinics in Thailand, Vietnam, or Singapore. However, during natural disasters or pandemics, everyone has to rely on the health care system of their own country, independent of personal economic resources.

The number of people living in absolute poverty is now surpassing two billion. ${ }^{17}$ The authors think that the experiences in Cambodia are relevant and of value for most under-developed countries.
Implementation of the given management system could save both limbs and lives. A post-traumatic amputation or disability is a worst-case scenario, especially for people living in poverty. In addition, it has been seen how the establishment of medical tools, triage protocols through simple classification systems, and mastering of reconstructive principles in limb salvage surgery have boosted the self-confidence and independence of local surgeons in the study region. 


\begin{tabular}{|l|l|}
\hline Inclusion Criteria & Exclusion Criteria \\
\hline 1. 8 - 79 years of age & 1. Traumatic amputation of the study tibia \\
\hline $\begin{array}{l}\text { 2. Open fractures of tibia classified GHOIS score meeting at least one of } \\
\text { the criteria: }\end{array}$ & 2. Complex pilon/plateau fractures \\
$\begin{array}{l}\text { a) Gustilo IIIA with GHOIS skin and bone score }<3 \\
\text { b) Gustilo IIIB with GHOIS skin and bone }>3\end{array}$ & \\
\hline $\begin{array}{l}\text { 3. Complication after plate or nail fixation maximum } 6 \text { weeks after primary } \\
\text { operation }\end{array}$ & $\begin{array}{l}\text { 3. Gustilo IIIC not salvageable or need for microsurgery reconstruction } \\
\text { with free flaps }\end{array}$ \\
\hline 4. Isolated open fractures in leg & 4. Complete bone defect more than $4 \mathrm{~cm}$ \\
\hline
\end{tabular}

Table 1. Inclusion and Exclusion Criteria for Study

Abbreviation: GHOIS, Ganga Hospital Open Injury Score.

Tajsic () 2022 Prehospital and Disaster Medicine

\section{The Gustilo classification}

\section{Type I}

Skin opening of $1 \mathrm{~cm}$ or less, quite clean.

Minimal muscle contusion. Low-energy injury

\section{Type II}

Laceration more then $1 \mathrm{~cm}$ long.

Extensive soft-tissue damage, flaps or avulsion. Simple transverse or short oblique fractures with minimal communition.

\section{Type III}

All grad type III injures are caused by

high-energy trauma.

\section{Type III a}

Extensive soft-tissue laceration may occur, bat the bone is covered by soft tissue after reduction of the fracture. Segmental fractures.

\section{Type III b}

Extensive soft-tissue with periostal stripping and bone exposure. Usually associated with massive contamination. Bone may be lacking. Impaired soft tissue not able to completely cover the bone. Plastic surgery is often required.

\section{The Ganga Hospital injury severity score}

\section{Type III c}

Vascular injury requiring repair

- Covering structures: skin and fascia
Wounds without skin loss
$\quad$ Not over the facture
$\quad$ Exposing the fracture

Tajsic @ 2022 Prehospital and Disaster Medicine

Figure 3. The Gustilo and Ganga Hospital Open Fracture Injury Severity Score.

Conclusion

The actual intervention demonstrates that skilled surgical teams can perform advanced reconstructive surgery in low-resource settings. The given fracture management program includes treatment with external fixation and functional bracing, combined with highlevel training of local surgeons and health workers. This combination provides a keystone in building up capacity for limb salvage surgery in rural settings. 


\begin{tabular}{|c|c|c|}
\hline Variables & Group I $(n=17)$ & Group II $(n=39)$ \\
\hline Mean Age (range) & $27.5(8-53)$ & $39.1(14-79)$ \\
\hline Number of Males (\%) & $15(88.2 \%)$ & $35(89.7 \%)$ \\
\hline Duration Orthosis: Mean (range) in Weeks & $16.6(6-44)$ & $21.2(8-48)$ \\
\hline Mean (range) to Union in Weeks & $29.5(14-56)$ & $44.0(16-96)$ \\
\hline
\end{tabular}

Table 2. Outcome Variables for Patients Classified to Group 1 (GHOIS $\leq 5)$ and Group II (GHOIS >5)

Note: The variables include age, gender, duration of treatment using the external fixator and orthosis, the time to union, the number of deep infections, and the number of flaps for all patients.

Abbreviation: GHOIS, Ganga Hospital Open Injury Score.

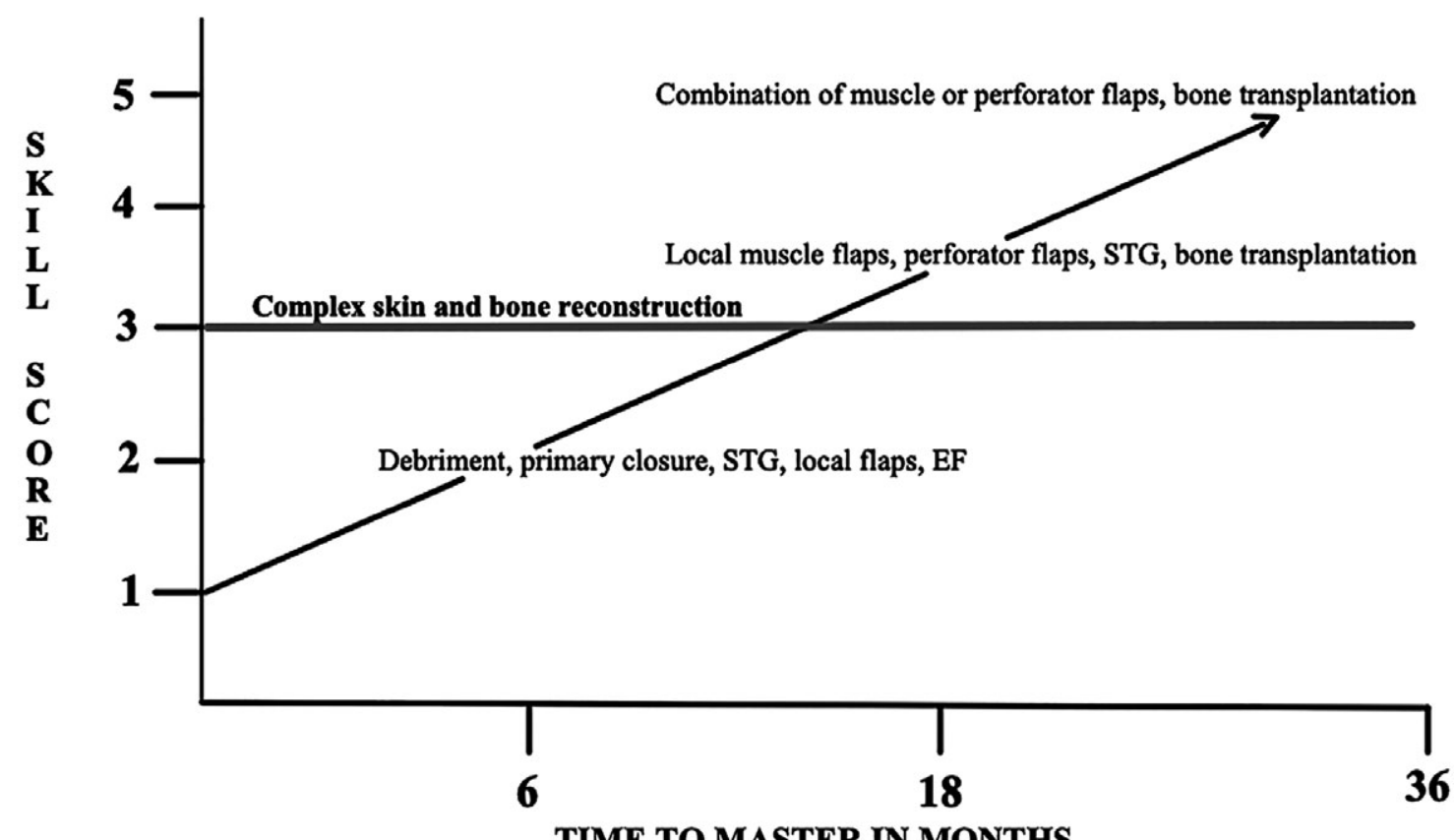

TIME TO MASTER IN MONTHS

Tajsic @ 2022 Prehospital and Disaster Medicine

Figure 4. Surgeon Skill Score in Mastering Operation Techniques in Lower Limb Reconstruction.

Abbreviations: STG, soft tissue graft; EF, external fixator.

Acknowledgements

The authors express thanks for the support given by the Trauma Care

Foundation in Cambodia and the kind support of the District Office of Health and the Military Hospital, Region 5, Battambang, Cambodia. They also thank Stefan Tajsic and Zoltan Tot for technical assistance in preparation of figures and tables.

\section{References}

1. IFRC. Cambodia: more deaths on the roads than in minefields. https://www.ifrc.org/ en/noticias/noticias/asia-pacific/cambodia/cambodia-more-deaths-on-the-roadsthan-in-minefields/. Accessed May 2021.

2. Cambodian News English. Traffic accidents, deaths, injuries increase from 2018. https://cne.wtf/2019/07/01/traffic-accidents-deaths-injuries-increase-from-2018/. Accessed May 2021.

3. Calder J, Mannion S. Orthopedics in Sri-Lanka post-tsunami. J Bone Joint Surg Br. 2005;87(6);759-761.

4. Tajsic NB, Sambath P, Nguon S, et al. Open fracture management in low-resource settings: a medical training experience in Cambodian hospitals. World J Surg. 2017;41(12):2981-2989.
5. Levin LS. The reconstructive ladder. An orthoplastic approach. Orthop Clin North Am. 1993;24(3):393-409.

6. Gustilo RB, Mendoza RM, Williams DN. Problems in the management of type III (severe) open fractures: a new classification of type III open fractures. J Trauma. 1984;24(8):742-746.

7. Rajasekaran S, Babu JN, Dheenadhayalan J, et al. A score for predicting salvage and outcome in Gustilo type-IIIA and type-IIIB open tibial fractures.J Bone Joint Surg Br. 2006;88(10):1351-1360.

8. Rajasekaran S, Dheenadhayalan J, Babu JN, Sundararajan SR, Venkatramani H, Sabapthy R. Immediate primary skin closure in type-III A and B open fractures. J Bone Joint Surg Br. 2009;91(2);217-224. 
9. Nanchahal J, Nayagam S, Khan U, et al. Standards for the Management of Open Fractures of the Lower Limb. London, UK: Royal Society of Medicine Press; 2009:24.

10. Tajsic N, Winkel R, Husum H. Distally based perforator flaps for reconstruction of post-traumatic defects of the lower leg and foot. A review of the anatomy and clinical outcomes. Injury. 2014;45(3):469-477.

11. Tetreault MW, Della Valle CJ, Hellman MD, Wysocki RW. Medial gastrocnemius flap in the course of treatment for an infection at the site of a total knee arthroplasty. JBJS Essent Surg Tech. 2017;7(2):e14.

12. Ahmad I, Akhtar S, Rashidi E, Khurram MF. Hemisoleus muscle flap in the reconstruction of exposed bones in the lower limb. $J$ Wound Care. 2013;22(11):635-642.

13. Papineau LJ. L'excision-greffe avec fermeture retardée délibérée dans l'ostéomyélite chronique (Excision-graft with deliberately delayed closing in chronic osteomyelitis). Nouv Presse Med. 1973;2: 2753-2755.

14. Brumback RJ, Jones AL. Interobserver agreement in the classification of open fractures of the tibia. The results of a survey of two hundred and forty-five orthopedic surgeons. J Bone Joint Surg Am. 1994;76(8):1162-1166.

15. Suksathien Y, Suksathien R. Clinical study of new design multifunction dynamic external fixator system for open tibial fracture. $J$ Med Assoc Thai. 2011;94(9);1084-1088.

16. Chaus GW, Dukes C, Hak DJ, Mauffrey C, Hammeberg EM. Analyses of usage and associated cost of external fixators at an urban level 1 trauma center. Injury. 2014;45(10);1611-1613.

17. Eide AH, Ingstad B, (eds). Disability and Poverty: A Global Challenge. Bristol, England: Policy Press, University of Bristol UK; 2011. 